\title{
"With the recent advents of gene-editing technologies, how can we establish ethical guidelines to prevent the exploitations of these technologies in applications that are outside of conventional medicine?"
}

The genetic technology known as CRISPR/Cas9 (clustered regularly interspaced short palindromic repeats/CRISPR-associated system 9) has revolutionized the field of gene editing and generated much excitement in the scientific community. While previous gene editing technologies have been resource-heavy and required significant specific expertise, CRISPR/Cas9 is relatively quick, simple, inexpensive, and widely available. The CRISPR/Cas9 system, naturally found as part of the bacterial immune system, recognizes foreign DNA and removes it with unparalleled precision and ease (1). Scientists have already adapted this technology in the laboratory to eliminate disease in animal models (2) and to edit human cells (3).

In humans, CRISPR/Cas9 can be used to edit somatic cells of the body, changing the genetic information in a subset of cells in a living human. There has been promising research in somatic CRISPR/Cas9 applications, such as its recent use in repairing a mutation in hematopoietic stem and progenitor cells $(4,5)$. In fact, clinical trials using CRISPR/Cas9 to alter immune cells for the treatment of cancer are already underway $(6,7)$.

This technology can also be used to edit human germline cells. Editing the genome of egg or sperm cells differs significantly from somatic cells, as it produces a change that would be in every cell of the resulting individual. This would result in a human whose genome has been edited even before birth, and these changes would be heritable and passed on to the next generation.

While somatic applications of CRISPR/Cas9 are advancing rapidly, the use of CRISPR/Cas9 in human germline cells has been much more controversial, and has essentially been put to a halt. The potential for misuse of this technology in the prenatal setting, and concerns over safety and unknown risks, has prompted the scientific community to call for a world-wide moratorium on the use of CRISPR/Cas9 in human reproductive cells, while international discussion and guideline development ensues (8).

While much of the hope associated with this tech- nology is centered on application to genetic syndromes, CRISPR/Cas9 could theoretically be used outside the realm of conventional medicine for enhancement or even cosmetic purposes, not just to alter a disease gene that runs in the family.

The moratorium on the use of CRISPR/Cas9 in germline cells comes, in part, from fear of exploitation of the technology; it is meant to provide time for guidelines and regulations to be in place before the technology is developed for non-conventional use. Discussion within the scientific and ethics communities, as well as research on stakeholder perspectives, including experts in the field, patients and families influenced by genetic disease, and the public, are essential in creating robust policy that takes all perspectives into account. Ethical considerations include social consequences, potential stigmatization of groups with disabilities, issues of access across different levels of socioeconomic status, and the exploitation of vulnerable individuals who might wish to pursue a cure. On the other hand, putting this technology on hold also means it will be difficult to learn more about it. Such fears led the United Nations Convention of Biodiversity to reject a moratorium on the application of CRISPR/Cas9 for gene drive (the ability of a gene to be inherited more frequently than Mendelian genetics would dictate, increasing its prevalence in the population) (9).

CRISPR/Cas9 gene editing technology is undoubtedly here to stay, and the technology is expanding. We are already seeing discoveries of variants of the CRISPR/Cas9 system, like the CRISPR/Cpf1, the CRISPR/ CasX and the CRISPR/CasY systems $(10,11)$. In addition, while a worldwide moratorium may be laudable, it has no legislative power or regulation on a global scale. As such, focused attention to build appropriate and meaningful policy, built on the foundations of international discussion and stakeholder perspectives, can lead us in the right direction. 


\section{References}

1. Doudna JA, Charpentier E. The new frontier of genome engineering with CRISPR-Cas9. Science. 2014 Nov 28;346(6213):1258096.

2. Yin $\mathrm{H}$, Xue W, Chen S, Bogorad RL, Benedetti E, Grompe M, et al. Genome editing with Cas9 in adult mice corrects a disease mutation and phenotype. Nat Biotechnol. 2014 Jun;32(6):551-3.

3. Liang $\mathrm{P}, \mathrm{X}$ Y Y, Zhang $\mathrm{X}$, Ding $\mathrm{C}$, Huang $\mathrm{R}$, Zhang Z, et al. CRISPR/ Cas9-mediated gene editing in human tripronuclear zygotes. Protein Cell. 2015 May 1;6(5):363-72.

4. DeWitt MA, Magis W, Bray NL, Wang T, Berman JR, Urbinati F, et al. Selection-free genome editing of the sickle mutation in human adult hematopoietic stem/progenitor cells. Sci Transl Med. 2016 Oct 12;8(360):360ra134-360ra134.

5. Ravin SSD, Li L, Wu X, Choi U, Allen C, Koontz S, et al. CRISPRCas9 gene repair of hematopoietic stem cells from patients with X-linked chronic granulomatous disease. Sci Transl Med. 2017 Jan 11;9(372):eaah3480.

6. Cyranoski D. Chinese scientists to pioneer first human CRISPR trial. Nat News. 2016 Jul 28;535(7613):476.

7. Reardon S. First CRISPR clinical trial gets green light from US panel. Nat News [Internet]. [cited 2017 Jan 26]; Available from: http://www.nature.com/news/first-crispr-clinical-trial-gets-greenlight-from-us-panel-1.20137

8. Bosley KS, Botchan M, Bredenoord AL, Carroll D, Charo RA, Charpentier $E$, et al. CRISPR germline engineering-the community speaks. Nat Biotechnol. 2015 May;33(5):478-86.

9. Callaway E. "Gene drive" moratorium shot down at UN biodiversity meeting. Nat News [Internet]. [cited 2017 Jan 26]; Available from: http://www.nature.com/news/gene-drive-moratorium-shotdown-at-un-biodiversity-meeting-1.21216

10. Zetsche B, Gootenberg IS, Abudayyeh OO, Slaymaker IM, Makarova KS, Essletzbichler P, et al. Cpf1 Is a Single RNA-Guided Endonuclease of a Class 2 CRISPR-Cas System. Cell. 2015 Oct 22;163(3):759-71.
11. Burstein D, Harrington LB, Strutt SC, Probst AJ, Anantharaman K, Thomas BC, et al. New CRISPR-Cas systems from uncultivated microbes. Nature [Internet]. 2016 Dec 22 [cited 2017 Jan 17];advance online publication. Available from: http://www.nature. com/nature/journal/vaap/ncurrent/full/nature21059.html

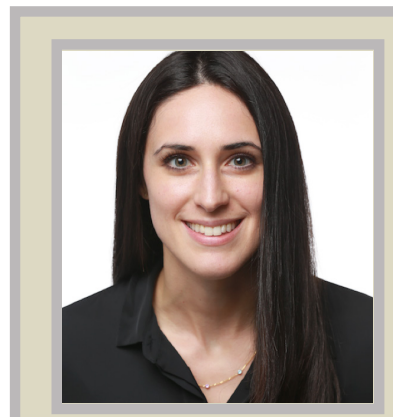

\section{Karen J. Jacob}

Karen Jacob holds a master's in Medical Genetics and has recently received a master's in Genetic Counselling from the University of British Columbia. Her broad research interests have led her to author academic publications in the fields of molecular biology, medical genetics and biomedical ethics and policy. Her most recent research has focused on elucidating policy recommendations for the use of CRISPR-Cas9 gene editing technology in human germline cells.

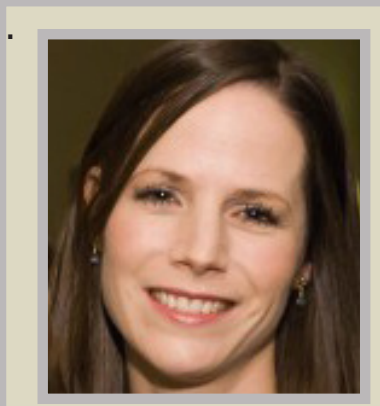

\section{Alice Virani}

Dr. Alice Virani is a clinical assistant professor in the Department of Medical Genetics at the University of British Columbia. Her research interests relate to the many ethical and social issues inherent within clinical practice and research in genetic and genomic medicine. 